\title{
Mortality variations as a measure of general practitioner performance: implications of the Shipman case
}

\author{
Stephen Frankel, Jonathan Sterne, George Davey Smith
}

Changes in the organisation of the NHS or in the management of health professionals are often made within the context of inquiries into specific medical catastrophes rather than through a measured process of policy formulation. Examples include changes in the scrutiny of psychiatric services after the Ely report into malpractice at a Cardiff hospital ${ }^{1}$ and, more recently, changes in doctors' self regulation after the high mortality in Bristol paediatric cardiac surgery. ${ }^{2}$ Harold Shipman's conviction for 15 murders committed during the course of his work as a general practitioner will result in several changes in the management of UK general practice. Some external monitoring of primary care is already routine. In the wake of the Shipman case there is pressure to introduce formal monitoring of mortality in general practitioners' patients. ${ }^{3}$ Here we consider the potential value of such an approach to identifying aberrant practice.

\section{Methods and results}

The average list size per general practitioner in England was 1866 in $1998 .^{4}$ The crude mortality in Britain is currently $1.1 \%$ a year. The table shows the number of deaths expected according to practice size, together with the minimum number of deaths for which the lower limit of a $99 \%$ confidence interval from the Poisson distribution would exclude the national rate. As there are some 9000 practices in England, the use of $99 \%$ confidence intervals would, by definition, necessitate the intense investigation of the $0.5 \%$ (approximately 45 ) practices annually above this limit. In larger practices 30-40 excess deaths a year would not be detected as statistically exceptional. Shipman's practice list of 3600 would allow an excess of 18 deaths a year above the average to pass as unremarkable, which is more than the 15 murders over three years he is currently convicted of (a murder rate of five per year) and also more than the high estimate of 175 murders over more than a decade, although repetitively elevated mortality, even if below the threshold, could, with extra effort, receive additional monitoring. Even if such monitoring were restricted to deaths that occurred outside hospital, random variation would mask considerable illegitimate mortality.

\section{Comment}

These findings highlight the difficulty of providing quantitative measures of quality, or of malpractice, within relatively small populations. Our estimates for the expected ranges of deaths within general practices are highly conservative, since different compositions of age, social class, and ethnic group in general practitioners' lists will strongly influence the numbers of deaths: rates could vary several fold between areas according to levels of deprivation, ${ }^{5}$ and local factors such as communicable disease and the presence of hospices or old peoples'

\begin{tabular}{|c|c|c|}
\hline \multirow{2}{*}{\multicolumn{3}{|c|}{$\begin{array}{l}\text { Expected and threshold }{ }^{*} \text { numbers of deaths each year in gene } \\
\text { practice patients according to practice list size } \\
\text { No of deaths among patients }\end{array}$}} \\
\hline & & \\
\hline List size (No of patients) & Expected & Threshold* \\
\hline 1000 & 11 & 21 \\
\hline 2000 & 22 & 36 \\
\hline 3600 & 40 & 58 \\
\hline 5000 & 55 & 76 \\
\hline 10000 & 111 & 140 \\
\hline 15000 & 166 & 201 \\
\hline 20000 & 222 & 263 \\
\hline
\end{tabular}

${ }^{*}$ Number of deaths for which the lower limit of $99 \%$ confidence interval excludes the national rate.

homes will also markedly influence mortality. Therefore, either more than $0.5 \%$ of practices would require intense scrutiny each year or the mortality level at which investigation is introduced would need to be raised, allowing the potential concealment of an even greater number of illegitimate deaths. Major changes in mortality in the smallest practices may reach the upper threshold more easily, but the trend towards discouraging singlehanded practice would make this less relevant. In contrast, aberrations in larger practices would be concealed by the wide confidence intervals and by the dilution of individual malpractice within grouped mortality statistics.

Whatever the appeal of seeking hard end points, such as mortality, in judging the quality of care, in the case of the performance of individual general practitioners these may only be a distraction from the more difficult task of measuring the more mundane attributes of care. Routine monitoring of mortality in general practice lists would have had limited benefit in highlighting the Shipman case, and therefore may have little value in preventing future occurrences. Such monitoring would create both false security and a statistical cacophony of false positive suspicion. Strengthened avenues for informal intelligence of aberrant practice from patients, relatives, other doctors, practice staff, pharmacists, coroners, undertakers, and others are the key protection against lethal doctors.

SF, JS, and GDS conducted the analyses and wrote the article. SF is guarantor for the study.

Competing interests: None declared.

Funding: None.

1 Rivett G. From cradle to grave: fifty years of the NHS. London: King's Fund,1998.

2 Smith R. Managing the clinical performance of doctors. BMJ 1999 ; 319:1314-5.

3 The trial of Harold Shipman. NewsUnlimited. www.newsunlimited.co.uk/ shipman (accessed 7 Feb 2000).

4 Department of Health. Statistics for general medical practitioners in England: 1988-1998. www.doh.gov.uk/public/medprac88-98.htm (accessed 7 Feb 2000)

5 Shaw M, Dorling D, Gordon D, Davey Smith G. The widening gap: health inequalities and policy in Britain. Bristol: Policy Press, 1999.

(Accepted 7 February 2000)
Department of Social Medicine, University of Bristol, Canynge Hall, Bristol BS8 2PR Stephen Frankel professor of epidemiology and public health medicine Jonathan Sterne senior lecturer in medical statistics George Davey Smith professor of clinical epidemiology

Correspondence to: S Frankel stephen.frankel@ bris.ac.uk

BMJ 2000;320:489 